\title{
A Smart Integrated Network for an Offshore Island
}

\author{
Eleanor Denny, Andrew Keane, Member, IEEE,
}

\begin{abstract}
This article examines the potential to create an energy independent smart network for an island community utilizing ocean and wind energy. The analysis involves the simulation of an extensive electrification of the heat and transport sectors on the island and the use of renewable energy to maximize the fuel and emission savings. This study involves a full renewable resource assessment for both wind and ocean devices. It also includes the design of a smart-network control algorithm to optimize the timing of electric vehicle charging and heat pump usage to exploit available renewable energy and minimize cost. Results indicate a dramatic reduction in total energy consumption through the electrification of the heat and transport sectors. For the case study system it is recommended that efficiency measures are adopted prior to the deployment of more advanced demand technologies and that air-source heat pumps should be prioritized over electric vehicle deployment due to the nature of energy demand on the island and the capital costs involved.
\end{abstract}

Index Terms-Ocean Energy, Wind Power Generation, Smart grid, Linear Programming.

\section{INTRODUCTION}

$\mathbf{O}$ FFSHORE island communities dependent on imported energy, either in electrical or fossil fuel form, are facing increasing economic pressures due to rising energy and transport costs. Many offshore islands have significant wind and ocean energy resources which, if harvested, should reduce costs and dependencies, yield inward investment and create employment opportunities. In fact in recent years there have been an increasing number of examples of small island communities aiming for energy independence through the development of local renewable potential.

Sams $\varnothing$ island in Denmark's Jutland Peninsula was one of the first offshore islands to pursue a strong renewable agenda. In 1997 the island declare its intent to rely on 100\% renewable energy for the island's needs. Without a direct subsidy from the Danish government, the island communities built a $€ 50$ million energy system with $80 \%$ of the capital raised from local investors [1]. Similarly Utsira, a remote island in the North Sea, $18 \mathrm{~km}$ off the coast of northern Norway, has become a demonstration community for energy independence with an energy system consisting solely of wind and hydrogen. When the wind turbines at Utsira are running at maximum output they produce more energy than the community requires. The surplus energy is used to produce hydrogen through water electrolysis which can then be sold in the electricity market or stored for use when wind output is low [2].

Eleanor Denny is with the Department of Economics, Trinity College Dublin, Dublin 2, Ireland, and can be contacted at dennye@tcd.ie, tel: +353 1 8961522. Andrew Keane is with the School of Electrical, Electronic and Communications Engineering, University College Dublin, Belfield, Dublin 4, Ireland (andrew.keane@ucd.ie) .

This work was carried out in collaboration with the Sustainable Energy Authority of Ireland (SEAI) as part of their pilot project on introducing electric vehicles to the Aran Islands (http://www.seai.ie).
Renewable projects at Bornholm island in Denmark are a prime example of the employment opportunites and investment potential arising from sustainable development. Bornholm is the largest 'non-bridged' island in Denmark and approximately $40 \%$ of its energy is produced through combined heat and power production plus wind turbines. Bornholm hosted the Nordic Wind Power Conference in September 2009 which illustrates a significant commercial opportunity for sustainable island power systems in the future.

A wide ranging study on the energy options for the Orkney Islands off the northern coast of Scotland was conducted in 2007 [3]. The Orkneys consist of 17 islands and have a population of approximately 20,000. This study included increased wind energy, biomass and solar thermal with a strong focus on control solutions to overcome network constraints and facilitate higher penetrations of wind energy.

The focus of the research in this study is on the Aran Islands off the west coast of Ireland. Ireland itself is pursuing ambitious renewable energy targets of $16 \%$ of total final energy consumption from renewables by 2020 , with $40 \%$ of gross electricity consumption from renewables by 2020 [4]. The Irish Government has also initiated an ambitious target of achieving $10 \%$ electric vehicle penetration by 2020 [5]. The Aran Islands off the west coast of Ireland have been considered by some as an ideal test site for the development of renewable energy across the whole of the island of Ireland. In addition to ample renewable potential, the Aran Islands have recently launched an electric vehicle and smart metering pilot trial. Thus, this study investigates a renewable driven, smart network solution for the Aran Islands and discusses the potential to scale the results to the island of Ireland.

\section{A. The Aran Islands}

As seen in Figure 1, the Aran Islands lie on the Atlantic coast of Ireland and consist of three island communities on Inis Mór, Inis Meáin and Inis Oírr (collectively referred to as 'the Islands' throughout this paper), with a total population of 1,225 in 2009. Due to their Atlantic location, the islands are very well exposed to the prevailing winds from the west/south west.

This study examines how the electrical, heating and transport needs of the communities on the Aran Islands can be met from sustainable sources and can be economically utilised through a renewable energy powered smart network. Figure 2 illustrates the per capita usage of energy fuels on the Aran Islands compared to the overall Irish residential sector for the year 2008. The information in Figure 2 is based on the fuel import information provided by the co-operatives on the Islands, who are responsible for the import and distribution of solid and liquid fuels for the island communities. Residential information for the Ireland is from [7]. 


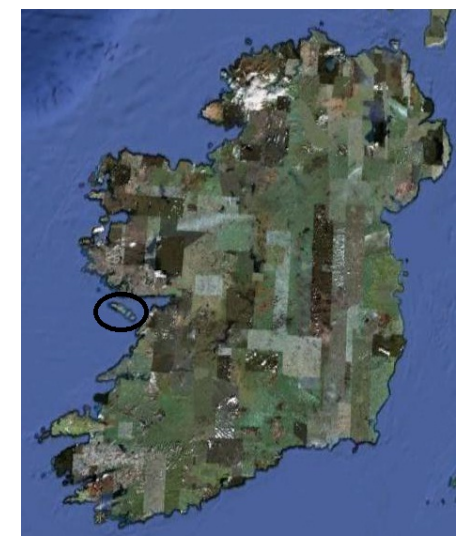

Fig. 1. Aran Islands location [6]

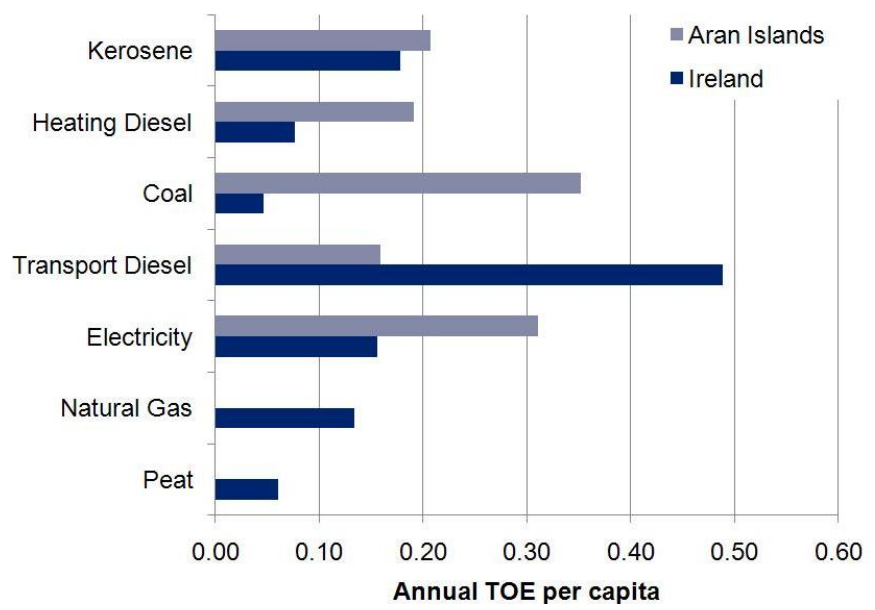

Fig. 2. Aran Islands annual fuel consumption per capita

From Figure 2 average total energy use per capita per annum on the Aran Islands is 1.22 TOE and for Ireland per capita is 1.14. The heating systems on the Aran Islands are based predominantly on diesel oil and kerosene fuelled central heating systems which explains the higher consumption of kerosene and heating oil on the Islands. Some of this difference may be due to a lack of access to natural gas and peat ${ }^{1}$. The use of coal on the Aran Islands is significantly more than on mainland Ireland which is somewhat expected as in general rural areas, such as the Aran Islands, consume significantly more coal than urban areas [8]. Also the Aran Islands is not in a smokeless fuel or low-smoke fuel area and can thus burn coal without restriction unlike in other parts of Ireland. However, it remains clear that the island communities use more fuel for heating in general than on mainland Ireland which, together with the traditional use of open fires, suggests that building stocks and insulation levels may be lower than on the mainland. Also, the Islands are exposed to high winds which may contribute to higher heating requirements.

With regard to transport, given the historical priority for agricultural transport fuels (and some local restrictions on petrol), diesel is the primary transport fuel in use today on

\footnotetext{
${ }^{1}$ Peat is an indigenous fuel in Ireland, traditionally burnt in open fires, like coal
}

the Islands. Transport fuel demand is significantly less on the Islands due to the shorter commuting distances covered by island residents compared to the mainland.

Electricity is imported to the Islands via a 3 MW cable connection to the Irish mainland which connects to the three Islands. Electricity consumption on the Islands is higher on average than on the mainland which could be due to a lack of access to natural gas. The primary industry on the Islands is tourism with the average population doubling during the summer months. As a result, the number of guesthouse per capita is significantly higher on average on the Aran Islands than for the mainland. These dwellings would be expected to utilise more heating and electricity (for example for electric showers) than standard residential dwellings, particularly in the peak tourist months.

In terms of electricity supply, since 2002 there has been an operational wind farm on Inis Meáin. The wind farm consists of three Vestas V27 $225 \mathrm{~kW}$ wind turbine generators with a maximum generation capacity of $675 \mathrm{~kW}$. The total yearly wind production currently equates to $39 \%$ of the total yearly electricity demand on the Islands. This level of renewable generation is significantly ahead of Ireland which met $9.4 \%$ of gross electricity consumption in 2007 with renewable generation, and wind generation represented $71 \%$ of this amount. Electrical imports for Ireland in 2007 represented $2.3 \%$ of generation compared to $61 \%$ for the Aran Islands [9]. The benefits of a connection to the mainland power system are clear, however, as highlighted in previous projects involving Island communities, the high cost of a submarine cable link to the mainland is often a driver for such hybrid island systems [3]. This economic constraint will drive the technical requirements of any system devised. In the case of the Aran Islands there is a $3 \mathrm{MW}$ submarine cable connecting it to mainland Ireland. In cases where there is currently no connection to the mainland power system an element of dispatchable generation capacity is required to maintain system balance and a reliable power supply [10]. As highlighted in Section I, numerous systems have been implemented around the world each with a different perspective, illustrating that a generic solution system is difficult to devise, as there is a wide range of possible generation and demand types, coupled with a variety of energy systems, be they gas, electricity or both.

In terms of $\mathrm{CO}_{2}$ emissions, the average annual emissions per dwelling on the Aran Islands is 11.4 tonnes which is over $40 \%$ higher than the Irish average of 8.1 tonnes of $\mathrm{CO}_{2}$ per dwelling [7]. This may be attributable to the higher use of open fires and heating oils on the Islands, which in turn may be associated with poorly insulated homes and a lack of experience with alternative options.

\section{Aran Islands Renewable Resource Assessment}

In order to implement a renewable-energy-driven smartnetwork proposal, it is first necessary to examine the renewable resource potential of the Islands. The resource potential assesses the technical resource, the practical resource and the accessible resource. The technical resource describes the total available renewable resource if the technical maximum 
number of standard generators were installed. The practical resource reduces the technical resource by accounting for physical constraints such as houses and roads which limit the number of generators that may be installed. The accessible resource further reduces the practical resource by discounting areas having special designations where generators may not be installed such as special areas of conservation (SACs).

\section{A. Aran Islands Wind Resource}

The Wind Atlas for Ireland [11] displays wind speed maps for the entire country at 50,75 and 100 metres above ground level representative of the hub heights of current and future wind turbine technology. Consistent with the methodology employed in [12] the following assumptions were made when assessing the technical wind resource on the Aran Islands:

- A 3 MW machine with a 75m hub height was assumed

- A spacing of 5 turbines per square kilometre was chosen

- Neglect sites with a long-term annual hourly mean wind speed of less than $7.5 \mathrm{~m} / \mathrm{second}$

The average wind speed for each island from the wind atlas was used to calculate the total energy per turbine that would be extracted in a single year. The resultant technically feasible wind resource was calculated as 2,650 GWh per annum (or 987 MW installed) in total across the three Islands.

While this figure shows a very large wind resource exists on the Aran Islands it is not possible to install wind turbines over the entire landmass of the Aran Islands. The practical resource seeks to reduce the technical resource by accounting for physical constraints which would prohibit the installation of wind turbines over much of the landmass of the Aran Islands. The practical wind resource is defined as the technical resource reduced to account for physical constraints such as airports, roads, lakes, electrical infrastructure as well as constraints related to proximity to urban settlements caused by visual impacts, noise and shadow flicker. In consideration of these constraints a buffer of approximately $200 \mathrm{~m}$ from urban settlement areas and airports was assumed to define non practical areas for installation of wind generators on each of the Islands. The practical wind resource is thus reduced to 1,599 GWh (591 MW installed).

The accessible resource is defined as the practical resource reduced to take account of areas of special protection where the development of wind generators is likely to be restricted. Special Areas of Conservation (SACs) are strictly protected sites designated under the EC Habitats Directive [13]. In Ireland the development of wind farms within areas designated as SACs is very difficult and it is anticipated that it would be most unlikely that a commercial scale wind development would be permitted within or in close proximity to an SAC. Natural Heritage Areas (NHAs) are areas which are protected in order to preserve important habitats for plants and animals of national and international significance. The development of wind farms within areas designated as NHAs may be permitted by the local authority although development may be conditional on an appropriate habitat management plan to enhance the protected habitats currently present on the site.

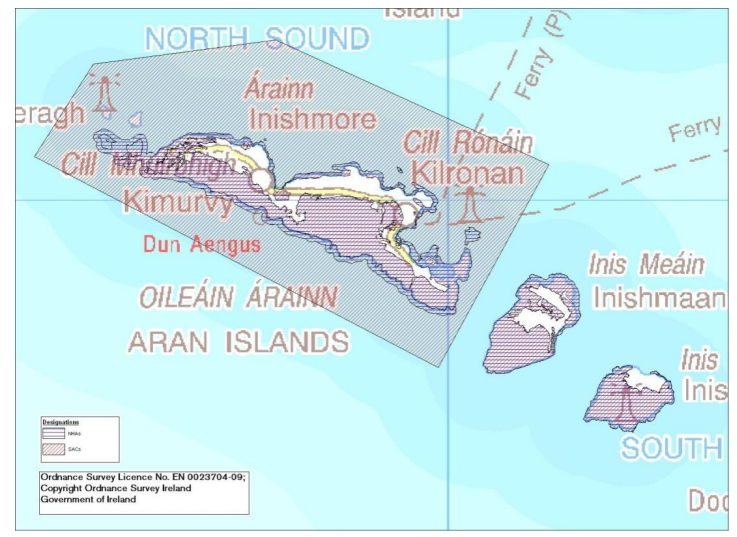

Fig. 3. Currently designated Special Areas of Conservation and National Heritage Areas on the Aran Islands [14]

The shaded areas in Figure 3 illustrated the currently designated SACs and NHAs on the Aran Islands. As illustrated, areas that currently hold no statutory designations (the nonshaded sections in Figure 3) are limited to only a small percentage of the area of the Aran Islands. These are the urban areas of the Islands which are considered non-practical and are not included in the area considered within the practical resource.

Thus, in conclusion, while the Aran Islands has a significant wind resource, the accessibility of this resource is entirely limited as the majority of the surface area of the Islands are designated as protected areas (either SACs or NHAs). The future accessible wind resource is therefore estimated at 0 MW.

The sole potential for a further increase in wind energy appears to be a re-development of the existing wind farm on Inis Meáin and the replacement of the existing turbines with more modern, larger units. This is not an unrealistic expectation as the existing wind turbines are coming to the end of their lifetime and are likely to be decommissioned in the coming years. Thus, this study assumes two scenarios for the redevelopment of this site, one where the local planning authority allows for the site to be expanded to install four Enercon E48 $800 \mathrm{~kW}$ wind turbines and the other where expansion of the site may not be permitted and the existing turbines are replaced by just one Enercon E48 $800 \mathrm{~kW}$ wind turbine.

\section{B. Aran Islands Tidal Resource}

As tidal flows are greatest at headlands and at points where tides are forced to flow through narrow channels, the narrow sounds separating the Aran Islands from each other (Gregory's and Foul Sounds in Figure 4) were considered in the technical resource assessment of tidal energy for the Aran Islands.

Previous estimates show tidal flow velocities are not expected to be greater than $0.5 \mathrm{~m} / \mathrm{s}$ in the areas surrounding the Aran Islands [16]. As tidal generators rely on the flow of water, minimum flow levels are necessary in order for these generators to be viable. Previous studies on tidal resources in Ireland [17] have limited potential resources by excluding sites with a current speed of less than $2 \mathrm{~m} / \mathrm{s}$. If the same approach 


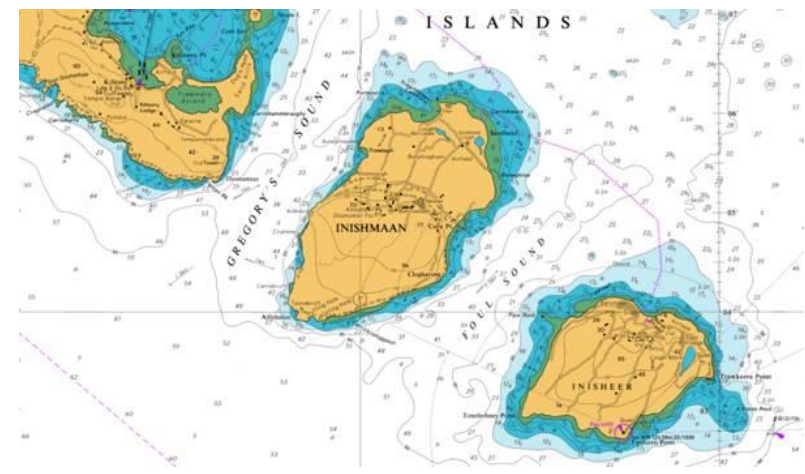

Fig. 4. Gregory and Foul Sounds between the Aran Islands [15]

is adopted here, we conclude that using current generation technology, there is no technical tidal resource around the Aran Islands.

While the practical and accessible resource is thus also zero, it is worth considering some of the practical constraints should future tidal generation technology allow for electricity generation from much lower tidal flows. The greatest tidal flow velocities exist in the Gregory's and Foul Sounds which are approximately $30 \mathrm{~m}$ deep. If future turbines were located 5 $\mathrm{m}$ above the sea bed and were in excess of $10 \mathrm{~m}$ in height (as is the case in most turbine designs) then there would only be $15 \mathrm{~m}$ clearance to the sea surface. This proximity to the surface can be problematic in areas of high wave exposure where wave induced flows cause large and oscillating loading on the turbine. Developers will tend not to site tidal generators in such areas.

The Aran Islands have high wave exposure with waves making contact with the seabed at a depth of just half their wave length. If a tidal turbine is positioned, at a best case, of $15 \mathrm{~m}$ to $25 \mathrm{~m}$ depth, waves with wave lengths of over $200 \mathrm{~m}$ would make contact with the tidal turbine. It is estimated that this is likely to be of significant concern over $20 \%$ of the time around the Aran Islands. This is likely to be too high a risk for a developer thus high wave exposures which exist around the Aran Islands further mitigate against the use of tidal energy generators for the Aran Islands. Using the assumptions of this study and other studies in the area, it is concluded that there is currently no accessible tidal generation resource available to the Aran Islands.

\section{Aran Islands Wave Resource}

In order to calculate the technical wave resource for the Aran Islands it is necessary to define a boundary around the Aran Islands. For the purpose of this resource assessment this boundary was taken to be $5 \mathrm{~km}$ from the shoreline. Using this boundary length and the seasonal average power flux values from the Irish Wave Energy Resource Atlas [18] it is possible to calculate the average theoretical wave power crossing the boundary for each island and the annual energy content in the waves. This is estimated at an average of $16,827 \mathrm{GWh}$ per annum.

In order to calculate the technically feasible resource it is necessary to consider the technical ability of devices to extract this energy from the waves. The technical resource is calculated by considering the characteristics of a commercially available device. As the most commercially advanced technology, the Pelamis wave device [19] was selected when calculating the technical resource available to the Aran Islands. Other wave energy extraction devices are under development and tests of such devices are ongoing in both Ireland and worldwide. It should be noted that the use of Pelamis in arriving at the technical resource in this study by no means excludes these other devices from this study and it is expected that the resource estimated can be extracted by any commercially available wave generator.

The Pelamis wave generator $30 \mathrm{MW}$ array proposed is 2.1 $\mathrm{km}$ long by $0.6 \mathrm{~km}$ deep and consists of $40 \mathrm{x} 750 \mathrm{~kW}$ wave generators with a nominal wave power flux of $55 \mathrm{~kW} / \mathrm{m}$. The average installed capacity per $\mathrm{km}$ is $14.2 \mathrm{MW} / \mathrm{km}$ and the capacity factor assumed is $25 \%$. The Pelamis device is designed to be installed in water with a depth of 50-150 m. When this limitation, together with the intersection of the boundaries of the three Islands, is considered, a technical wave resource for the Aran Islands of $192 \mathrm{GWh}$ per annum (22 MW installed) results.

The practical wave resource is not considered to be greatly reduced from the technical resource as the water depth limitations have already excluded the areas to the mainland side of the Aran Islands. The technical resource identified does not conflict with Department of Defence danger zones, marine traffic separation zones, floating buoys, lighthouses, navigation beacons, navigation channels, near shore anchorage regions, submarine cables, weather buoys or wind farm zones. For the purpose of this study the technical resource was reduced by $20 \%$ to account for unknown practical limitation which could restrict the actual deployment of all the technical wave resource identified above.

The accessible wave resource in this study accounts for National Heritage Areas and Special Areas of Conservation on or surrounding the Aran Islands. National Heritage Areas do not extend past the shoreline of the Aran Islands however a Special Area of Conservation does extend from Inis Mór to the seaward side of the island. The boundary considered in this study is taken to be $5 \mathrm{~km}$ from the shoreline of Inis Mór and thus should extend past the existing Special Area of Conservation. While the practical wave resource on the Aran Islands does not appear to conflict with areas having special designations, environmental decisions by the relevant authorities may result in a reduction in the true accessible wave resource on the Aran Islands.

Ocean energy resources are at varying stages of maturity, with some test deployments in place around the island of Ireland [20]. The timeline for commercial viability is still uncertain but the devices can be divided into two broad categories, wideband and narrowband devices [21]. This refers to the relationship between the power output of the turbines and the sea states/energy. What is clear at this stage is that there has yet to be convergence on the turbine design and technology. The challenging environments which these turbines will be deployed in will present a barrier to the successful commercialisation of these devices [22]. Equipment failures 
and time to repair remain real challenges to the harvesting of wave energy. Significant data measurements from buoys around the Island of Ireland has taken place in preceding years by the Irish Marine Institute [20]. The relationship between wave energy output and wind power output is central to any consideration of a control solution to optimise their usage. Previous work has examined this relationship in detail and determined that a clear relationship but not perfect correlation exists between wave and wind energy output [21].

\section{Smart Energy Network Proposal}

The current energy needs for the Aran Islands comprise heat, transport and electrical energy. These energy needs are currently met through the importation of solid fuels and electricity from the Irish mainland, with an existing wind farm supplying some of the electrical demand. This study investigates the development of a smart grid system which would utilise the existing wind resource and possible additional wind and ocean resource to increase the local utilisation of renewable energy on the Aran Islands and reduce the importation of fuel and electricity from the mainland. A key component in this vision is the electrification of the transport fleet (through the use of electric vehicles) and electrification of the heating components (by using heat pumps). Essentially, this would shift solid fuel demand to electricity demand which could then be supplied by electricity generated from renewable resources. This vision requires a central energy optimisation tool which would optimise the charging of electric vehicles and heat pumps based on the available local renewable generation.

\section{A. High Level Approach}

An Energy Optimisation Model (referred to as the 'Model' in this paper) is developed for this task and it optimises the energy supply for the Aran Islands through consideration of the available hourly renewable energy and the residential electricity price. It considers electricity, heat and transport demands as integrated loads rather than as distinct components and synergises the usage patterns of certain flexible elements of the demand to coincide with available renewable energy generation and time of day prices. The primary objective of the optimisation is to maximises the usage of renewable energy locally, with a secondary objective to deliver a least cost demand dispatch. These objectives were ordered in this manner due to a desire from both the islanders and policy makers to maximise the usage of local renewable energy, rather than necessarily providing a 'least-cost solution'.

\section{B. Base Demand and Flexible Demand}

It is important at this point to distinguish between demand which could theoretically be scheduled for any hour of the day (for example the charging electric vehicles) versus demand which must be met at a particular time (for example electricity required for an electric shower before work or for cooking dinner in the evening). In other words, energy demand is split into two categories: a base level demand which must be met in every hour of every day and a flexible element which must be satisfied daily but the timing of which can vary.
Heat is currently supplied predominantly by diesel, kerosene and coal. This analysis will not consider the addition of further heat supply from these sources but rather the replacement of some of the diesel/kerosene heating by air source heat pumps. The charging of these heat pumps will represent the flexible element of heat demand in the model. The balance of heating demand (i.e. that not met by heat pumps) will comprise the base heat component.

All private vehicles on the Islands are currently fuelled by diesel. The flexible element of the transport demand in the model is considered to be the charging of electric vehicles. The balance of transport demand (i.e. from those households without an electric vehicle) will be met entirely by diesel and is considered to be the base transport demand. It is assumed that the same number of kilometres will be travelled regardless of whether the individual is driving a conventional diesel vehicle or an electric vehicle. Thus, the size of the flexible transport demand will be determined by the assumed penetration of electric vehicles on the island and the average electricity consumption for a complete battery charge.

The flexible electricity demand element consists of the demand for electric vehicle charging and heat pump charging. The timing of this 'flexible' element will be optimised in the model to coincide with times of high renewable output and/or low electricity prices. If there is insufficient renewable generation to meet the flexible element on a daily basis, the balance will be met from electrical imports. The net effect is a transfer of a portion of the heat and transport demand to electricity demand. The base electricity demand is that portion of electricity demand which is not from electric vehicles or heat pumps. Figure 5 illustrates the high-level structure of the methodology with demands being split into base and flexible elements.

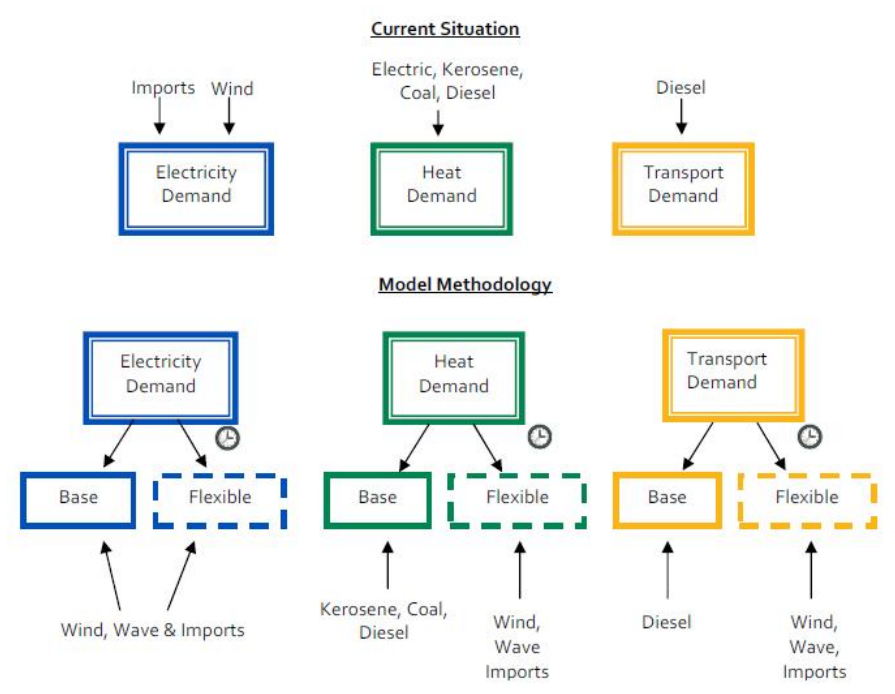

Fig. 5. Current energy system on the Aran Islands and the proposed high level methodology

The flexible elements of demand are aggregated within the model and it is assumed that this task would be carried out by an electricity supplier in reality. This supplier would actively control the flexible portions of the demand and implement 
the optimisation described and send a charging signal to the electric vehicles and heat pumps (most likely through a smart meter). It is envisaged that households with electric vehicles or heat pumps would be designated as smart households and would sign up to such a scheme with their electricity supplier.

Electricity generation on the Islands is currently supplied by wind generation and electrical imports from the mainland. For the purposes of this study increasing penetrations of wind and wave generation will be considered. It is assumed that the renewable energy is supplied to the island grid and the residents of the Islands pay the same price for the electricity supplied by renewables as they do for electricity from any other source, as is the case for all consumers in mainland Ireland. In the cost-benefit analysis (Section V-A), revenues from the renewable generators are considered. Depending on the ownership structure of the renewables on the Islands, some of this revenue could be redistributed to the island residents to offset some of their energy costs.

For the purposes of illustration, a perfect wind and wave forecast is employed in this paper. As the proposed method will involve operation on a 15 minute to hourly basis, the dispatch decision could be made on an individual basis from time step to time step, thus not requiring a forecast at all, but would be dependent on the wind and wave conditions at the time. The time of use tariffs are also pre-determined and are known day ahead and at each time step allowing consideration of this input in the secondary optimisation of minimum cost.

The Model assumes that electrical imports/exports are constrained only by the capacity of the $3 \mathrm{MW}$ line. Electrical imports are considered as a slack variable which can be either positive (importing electricity) or negative (exporting surplus renewable energy). Thus, the hourly flows on this line are an output of the Model rather than an input.

\section{Optimising Supply and Demand}

In order to construct the Energy Optimisation Model to simulate the energy scenarios for the Aran Islands it was necessary to obtain hourly time series information per household on electricity demand, heat demand and transport demand. As this hourly data was unavailable prior to this study, these time series were simulated using information on daily, monthly and annual usage patterns for which data was available. The full methodology for the creation of these hourly time series can be found in [23].

Hourly time series data was also required for electricity prices and renewable energy output. For electricity prices, the ESB (leading Irish electricity supplier) nightsaver tariff is used which equates to a price of $€ 0.077 / \mathrm{kWh}$ during the hours of midnight to $7 \mathrm{am}$ and a price of $€ 0.15 / \mathrm{kWh}$ during other hours. During the months of April to October inclusive, the lower ESB night-rate is extended by one hour from 7am until $8 \mathrm{am}$ to account for daylight saving.

An hourly time series of wind generation on the Aran Islands is also required and this was provided for the existing $675 \mathrm{~kW}$ Aran Islands wind farm for the year 2007. Aqua Marine Power provided a sample hourly time series for their wave generator Oyster II with an assumed capacity 1.8 MW.
The wave farm has an assumed load factor of 54\%. This load factor may be artificially high due to the turbine being significantly smaller than the potential resource, however, due to a lack of more detailed data this load factor is assumed for all wave generation in this study.

Figure 6 shows the average monthly output of the $675 \mathrm{~kW}$ existing wind farm and the sample output for the $1.8 \mathrm{MW}$ wave device from Aqua Marine Power. Also illustrated is average electricity demand per month on the islands in 2007. This shows that the average monthly wave generation output appears to be more aligned with seasonal demand.

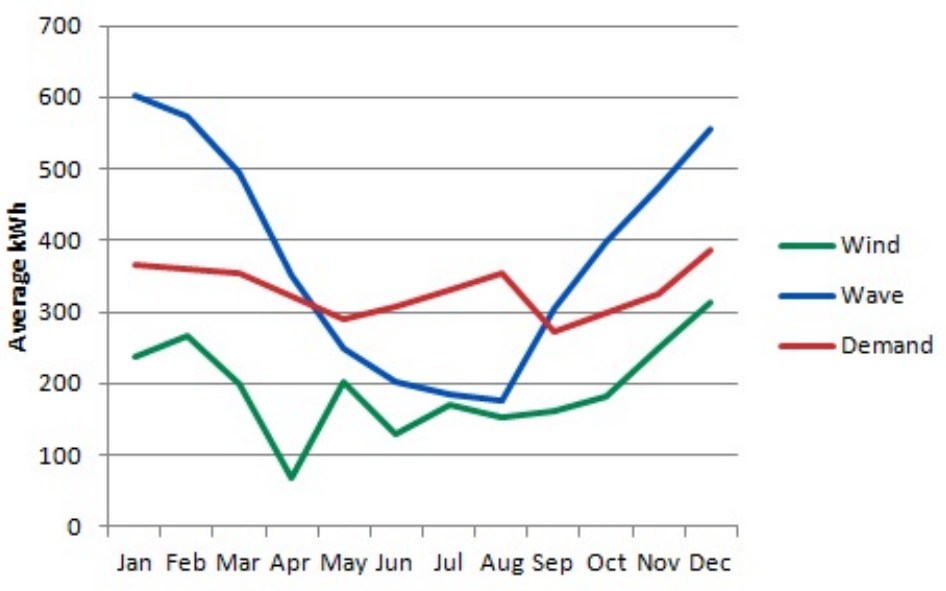

Fig. 6. Average monthly output of renewable devices and monthly demand in the year 2007

Using the hourly time series and the assumed levels of flexible heat and transport, the Model optimises the energy usage of the Islands over a sample year. There are two objectives to the method. The primary one is to dispatch the demand according to the available surplus renewable energy and the secondary objective is to minimise the cost utilising a linear programme formulation. As illustrated in the flowchart in Figure 7, the first objective is determined by an iterative process which sweeps through the day ahead on an hourly basis dispatching the flexible demand elements. This initial dispatch then forms constraints for the secondary linear programming optimisation. This secondary objective dispatches any remaining flexible demand elements subject to the constraints imposed by the primary objective.

To illustrate how the optimisation model works, Figure 8 illustrates a sample day of operation of the model on a day with high renewable output. It can be seen that the net renewable output (renewable output left after Base Demand has been met) occurs in the early hours of the morning at which time the flexible demand elements are therefore dispatched, i.e. electric vehicles and heat pumps.

Figure 9 shows a day where there is no surplus renewable evident, in which case the optimisation reverts to the least cost method, corresponding to the early hours of the morning when the off-peak night tariff is active. 


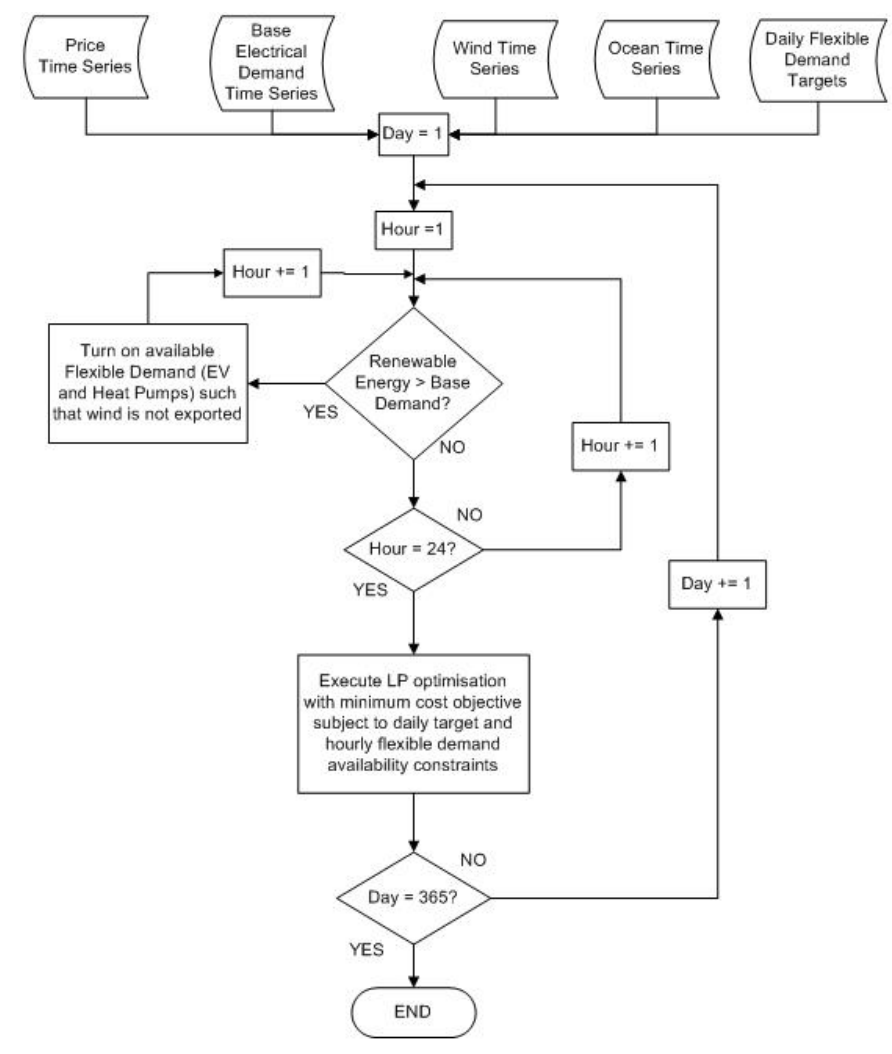

Fig. 7. Energy Optimisation Model Methodology

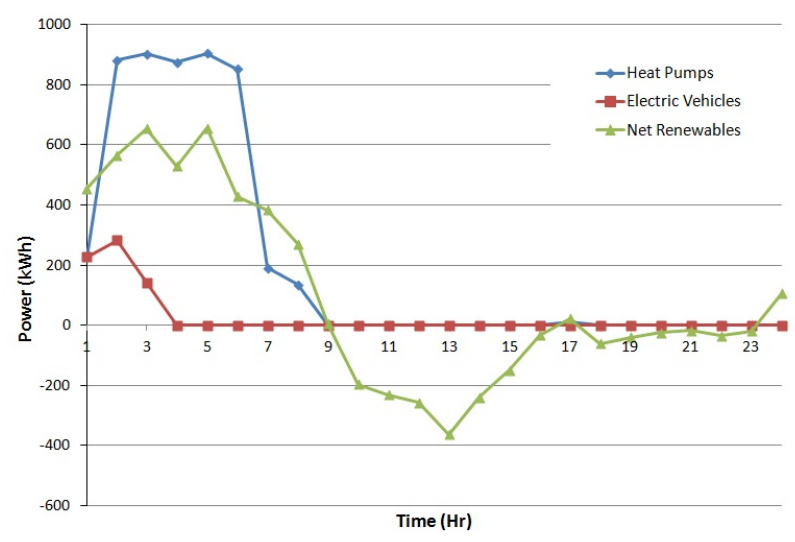

Fig. 8. Sample day of operation (high renewables)

\section{SCEnARIOS}

The following five scenarios are run in the Model and the results for these scenarios are discussed in the subsequent sections.

1) Base Case - situation on the Aran Islands for 2008

2) Efficiency Case - base case with efficiency measures of $10 \%$ electrical efficiency and 30\% thermal efficiency (all subsequent scenarios also assume this setup). This is to represent the use of more efficient electrical appliances and improvements in housing insulation. These are the cheapest methods of reducing energy demand and are likely to be considered prior to the development of

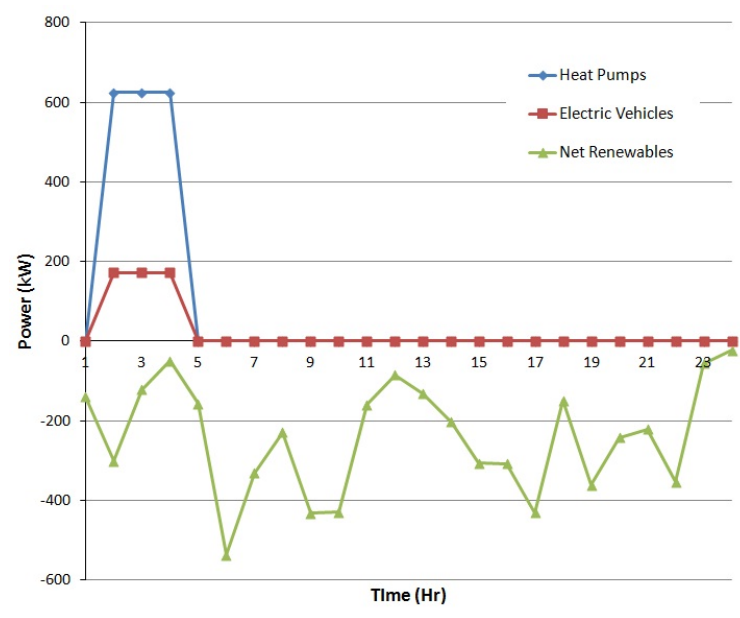

Fig. 9. Sample day of operation (low renewables)

renewable generation.

3) Wind 50\% - A wind energy penetration of $3.2 \mathrm{MW}$ (through expansion of existing site with 4 Enercon E48 $800 \mathrm{~kW}$ wind turbines) combined with a $50 \%$ penetration of demand technologies i.e. 50\% of all houses with heat pumps, $50 \%$ of all vehicles as electric.

4) Wind+Wave $50 \%$ - A wind energy penetration of 800 $\mathrm{kW}$, a wave energy penetration of $1 \mathrm{MW}$ combined with a $50 \%$ penetration of demand technologies.

5) Wind+Wave $100 \%$ - A wind penetration of $800 \mathrm{MW}$, wave penetration of $1 \mathrm{MW}$ and a $100 \%$ penetration of demand technologies i.e. the same as scenario 4 but with $100 \%$ of households with heat pumps and electric vehicles.

In scenarios 3, 4 and 5 heat pump and electric vehicle technology is assumed to be deployed. The assumptions regarding the design of the heat pump system are listed in Table I. The heat pump system considered here assumes that a storage vessel is employed so that heat may be generated at the optimal time as decided by the Energy Optimisation Model and stored for later use.

TABLE I

ASSUMED AIR SOURCE HEAT PUMP PARAMETERS

\begin{tabular}{|l|c|}
\hline Characteristic & Value \\
\hline \hline Coefficient of performance & 3.00 \\
\hline Electrical Rating & $3.50 \mathrm{~kW}$ \\
\hline Storage Volume & $55 \mathrm{kWh}$ \\
\hline $\begin{array}{l}\text { Additional daily heat input required } \\
\text { to account for storage losses }\end{array}$ & $2.00 \mathrm{kWh}$ \\
\hline
\end{tabular}

The coefficient of performance states the $\mathrm{kWh}$ of heat energy that is produced per $\mathrm{kWh}$ of electrical energy. The electrical rating of the heat pump defines the maximum power and thus the maximum per hour heat that may be produced by the system. The storage losses comprise the heat energy that is dissipated over 24 hours and thus acts to increase the total amount of heat that must be stored by the system to provide the underlying heat demand. 
Each house with a heat pump will also need an accumulator tank. It is estimated that with a temperature differential of $40^{\circ} \mathrm{C}$, a 1,500 litre accumulator will store approximately 70 $\mathrm{kWh}$ of heat energy, enough to provide full heating and hot water requirements for a reasonably well insulated 4 bedroom detached house. Thus, in the roll out of heat pumps on the Aran Islands it is recommended that a 1500 litre accumulator tank be installed with each heat pump.

The Renault Kangoo Express Z.E. was identified as a potential light electric vehicle for use on the Islands. This vehicle will have a lithium-ion battery and a charge time of 6 to 8 hours based on a $220 \mathrm{~V}$ supply voltage. This vehicle has an expected battery capacity of $20 \mathrm{kWh}$, which translates to an average power demand of $2.8 \mathrm{~kW}$. The range of the vehicle is $160 \mathrm{~km}$. The motor outputs $44 \mathrm{~kW}$, with a maximum motor speed of 12,000 rpm. This Renault Kangoo is expected to be launched in 2011. The specifications for a standard electric vehicle with a Lithium (Li) battery are shown in Table II.

TABLE II

ELECTRICAL CHARACTERISTICS OF STANDARD LITHIUM-ION BATTERY

\begin{tabular}{|l|c|}
\hline Max kW demand & $3.0 \mathrm{~kW}$ \\
\hline $\mathrm{kWh}$ & $20 \mathrm{kWh}$ \\
\hline Charge profile & $6-8$ hours \\
\hline
\end{tabular}

The depth of discharge is a key factor in battery lifetime. Manufacturers will typically limit the depth of discharge in the vehicles such that the battery is not fully discharged, as this would reduce the battery lifetime. As a result it is assumed that the electric vehicles will consume their full rated power for the duration of the charge cycle. The standard self discharge rate of an electric vehicle is typically $0.2 \%$ per day.

\section{RESULTS}

The Model was run for each of the scenarios described in Section IV and the results in terms of total annual energy consumption, $\mathrm{CO}_{2}$ emissions and total fuel costs are presented here.

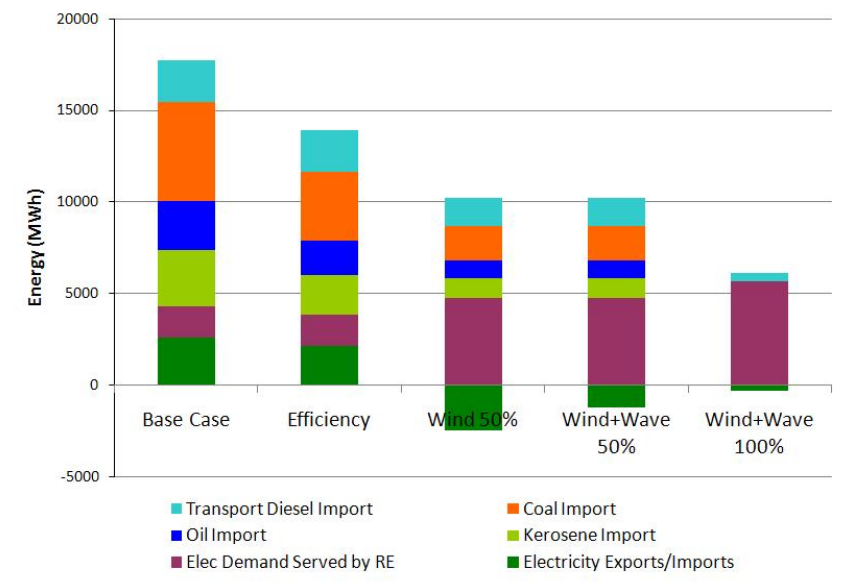

Fig. 10. Annual energy consumption for the Islands under each scenario

The 'Efficiency' scenario applies $10 \%$ electrical efficiency gains and $30 \%$ thermal efficiency gains to the Base Case which results in the expected reduction in annual energy demand. Moving from the 'Efficiency' scenario to the 'Wind 50\%' scenario we can see a dramatic reduction in energy demand. This is due to the replacement of $50 \%$ of the vehicle fleet with electric vehicles and heat pumps in 50\% of houses. It is assumed in the model that households still drive the same number of kilometers every day as they would with a conventional vehicle and still heat their houses for the same number of hours each day so this reduction in total energy demand is due to the significantly improved efficiency of these technologies over the status-quo.

Total energy consumption is the same between scenarios 'Wind 50\%' and 'Wind + Wave 50\%' as they have the same level of installed demand technologies. 'Wind+Wave 50\%' has a lower level of installed renewables (1.8MW versus $3.2 \mathrm{MW}$ in scenario Wind $50 \%$ due to the high load factor of the assumed wave device), thus it results in a lower level of net exports. In addition, the timing of electric vehicle and heat pump charging is different to the 'Wind 50\%' scenario which contributes to the lower net exports. The wave output time series is marginally more closely aligned to demand patterns than in the wind only scenario resulting in fewer periods of export/import.

In Scenario 'Wind+Wave 100\%' it is assumed that all vehicles are electric. However, there are a number of large machines on the Islands which use transport diesel and it is assumed that these cannot be converted to electric. Thus, there remains a small transport diesel demand in this scenario.

The reductions in total energy demand have a knock-on impact on $\mathrm{CO}_{2}$ emissions as can be seen in Figure 11.

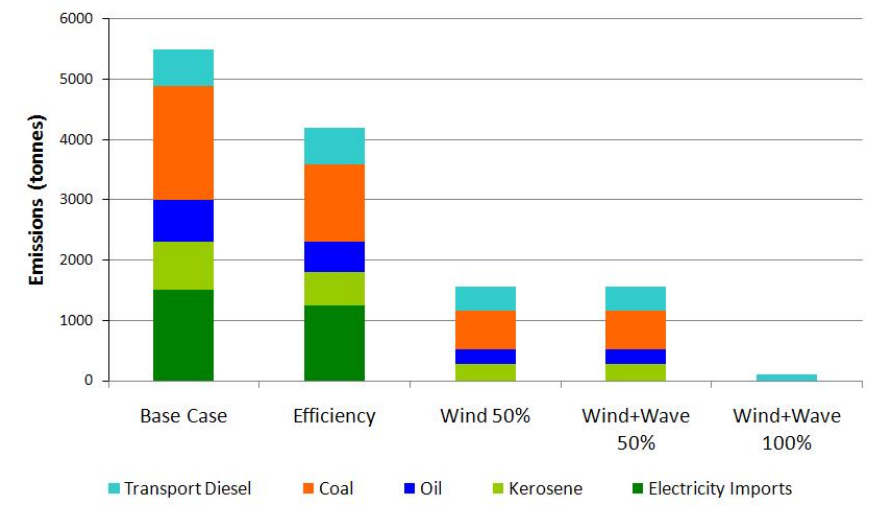

Fig. 11. Annual carbon dioxide emissions for the Islands under each scenario

In Figure 11, emissions of $\mathrm{CO}_{2}$ for electricity imports are based on the average Irish power system level of $0.58 \mathrm{~kg} \mathrm{CO}_{2} /$ $\mathrm{kWh}$. The only emissions in Scenario 'Wind+Wave 100\%' are from the machinery on the island which cannot be converted to electric. All other technologies are electric and $100 \%$ of demand is met from renewable resources (as can be seen from Figure 10, all three renewable scenarios result in net export of renewable energy).

The reduction in total energy demand also results in savings in the purchase of conventional fuels, although electricity consumption increases in any scenarios assuming electric 
vehicles and heat pumps. Fuel savings are calculated based on the following actual fuel costs for the Aran Islands in 2008 provided by the Co-operative.

TABLE III

ASSUMED FUEL COSTS

\begin{tabular}{|l|c|}
\hline Fuel & Price \\
\hline \hline Coal (per kg) & $€ 0.25$ \\
\hline Oil (per litre) & $€ 0.76$ \\
\hline Kerosene (per litre) & $€ 0.77$ \\
\hline Transport diesel (per litre) & $€ 0.75$ \\
\hline Electricity (per kWh) & $\begin{array}{c}€ 0.077 \text { (off-peak) } \\
€ 0.15 \text { (peak) }\end{array}$ \\
\hline
\end{tabular}

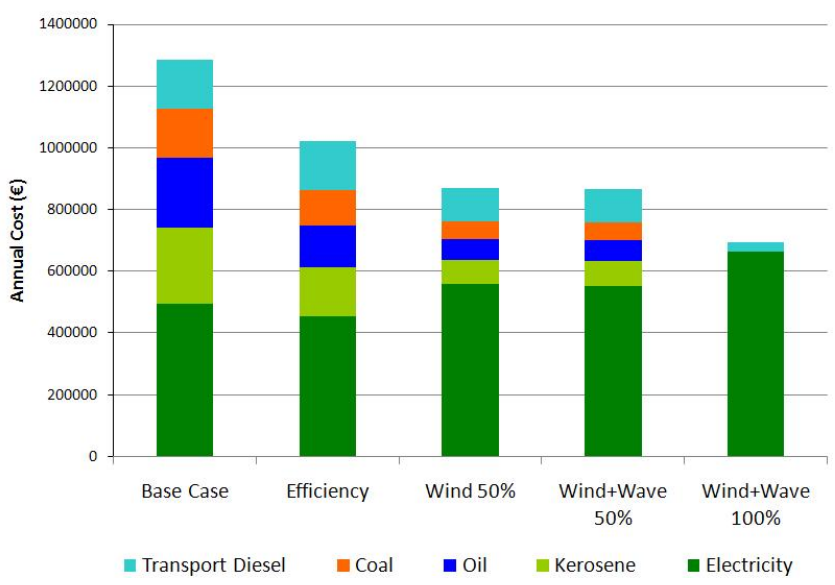

Fig. 12. Annual fuel costs for the Islands under each scenario (excluding capital costs)

It can be seen that the introduction of electric demand technologies reduces overall fuel costs. There is a marginal reduction in costs between scenarios 'Wind 50\%' and 'Wind+Wave $50 \%$ ' which is due to slightly more renewable energy output coinciding with the lower night-time electricity tariff in the latter scenario.

\section{A. Cost-Benefit Analysis}

In order to evaluate the net benefit of each scenario it is necessary to consider the costs of installing the assumed renewables and demand technologies. Table IV illustrates the assumed capital and operation and maintenance costs for the various technologies assumed.

Wind turbine costs are from [24] and are inflated from 2006 values using the Harmonised Consumer Price Index [25]. It is likely that this figure is somewhat lower than the current 2011 installation costs, however, since any further wind turbine development on the Aran Islands is likely to take place at an existing wind farm location it is thought that there would be some efficiencies to be gained from using existing grid connections and associated infrastructure. Hence this slightly lower capital cost is assumed to hold.

Wave turbine capital costs are based on the Pelamis device [26] but operation and maintenance costs were unavailable.
TABLE IV

ASSUMED COST INFORMATION FOR THE VARIOUS TECHNOLOGIES $€ 2010$

\begin{tabular}{|l|c|c|}
\hline Technology & $\begin{array}{c}\text { Capital cost } \\
\text { (inc installation) } \\
\text { per MW installed }\end{array}$ & $\begin{array}{c}\text { Annual operation } \\
\text { and maintenance } \\
\text { costs }\end{array}$ \\
\hline Wind turbine & $€ 646,629$ & $0.016 / \mathrm{kWh}$ \\
\hline Wave turbine & $€ 2,345,100$ & $0.032 / \mathrm{kWh}$ \\
\hline Renault Kangoo EV & $€ 24200$ & $€ 1600$ \\
\hline Air source heat pump & $€ 6225$ & $€ 100$ \\
\hline Insulation (attic \& cavity wall) & $€ 2000$ & - \\
\hline Electrical efficiency & $€ 60$ & - \\
\hline Smart meter & $€ 210$ & $€ 60$ \\
\hline
\end{tabular}

The O\&M costs for the wave device are thus assumed to be similar to an equivalently sized off-shore wind turbine, assumed to be twice as expensive as onshore wind.

For the electric vehicle, capital costs are based on Renault's recommended retail price of $€ 20,000$ including Irish VAT tax rate of $21 \%$ [27]. Annual operation and maintenance costs are based on estimated insurance costs and Renault's battery leasing programme at $€ 72 /$ month (excluding tax). Electric vehicles are currently exempt from vehicle registration tax in Ireland thus this cost is not included.

The air source heat pump capital cost information is from [28], [29] and includes the cost of the assumed accumulator tank. It is recommended that these air pumps are serviced every four years at an expected cost of $€ 400$ per service.

Sustainable Energy Authority of Ireland estimate that up to $30 \%$ of the heat produced in a house escapes through an uninsulated roof [30]. Thus, in order to provide a $30 \%$ improvement in thermal efficiency (as assumed in Scenarios 2 - 5) it is assumed that any uninsulated houses on the Aran Islands will install attic insulation. Since some houses will already have attic insulation some cavity wall insulation may also be required to achieve a further $30 \%$ reduction in these homes. The anticipated cost of insulation is averaged out at $€ 2000$ per household [30]. Electrical efficiency to reduce electricity demand by $10 \%$ is anticipated to involve the replacement of light fittings with energy saving bulbs and a more conservative approach to utilising electrical appliances e.g. switching-off appliances when not in use. The cost involved assumes an average cost of $€ 6$ per energy efficient light bulb and the replacement of approximately 10 bulbs per house.

The Commission for Energy Regulation in Ireland recently conducted a smart meter trial in 6000 Irish households. Cost data for the required smart meter for scenarios 3 - 5 is derived from the results of this trial [31]. This trial estimates that cost of the meter, its installation in a rural location, the wireless communication technology and the resolution of any technical issues on installation will cost on average $€ 210$ per dwelling. The annual O\&M costs account for likely communications costs via a power line carrier.

Using the above assumptions, the additional capital costs of each scenario over the base case are shown in Table V. The annualised and net present value (NPV) costs are assumed over a 15 year period with a discount rate of $6 \%$.

These costs must then be balanced against the benefits of 
TABLE V

TOTAL CAPITAL COST OF EACH SCENARIO $€ 2010$

\begin{tabular}{|l|c|c|}
\hline Scenario & NPV of Total Cost & Equivalent Annual Cost \\
\hline 2. Efficiency Case & $€ 966,140$ & $€ 99,476$ \\
\hline 3. Wind 50\% & $€ 14,719,856$ & $€ 727,525$ \\
\hline 4. Wind+Wave 50\% & $€ 16,003,103$ & $€ 806,389$ \\
\hline 5. Wind+Wave $100 \%$ & $€ 24,768,925$ & $€ 1,186,309$ \\
\hline
\end{tabular}

each scenario. The quantifiable benefits are the savings on fuel expenditure as a result of a reduction in total energy consumption. The fuel savings benefits are valued at the prices shown in Table III. The renewables and demand technologies also provide $\mathrm{CO}_{2}$ emissions savings, which are valued at $€ 20 /$ ton. It is unclear how this benefit could be recouped by the island community in reality but this cost-benefit analysis will consider societal welfare rather than the distributional impacts of the costs/benefits, thus $\mathrm{CO}_{2}$ emissions savings are included.

The renewable technologies will also receive a revenue stream from participating in the wholesale electricity market. Thus, Table VI also includes indicative renewable energy revenues. If the renewable generators are owned by private companies it is unlikely that this revenue would be realised by the Island residents. However, if the turbines are owned by the Island residents (for example through the co-operative), then these revenues could be distributed to the residents and would form part of the benefits of the scheme.

Table VI illustrates the annual benefits and also the net present value of the benefits over a 15 year period with an assumed discount rate of 6\% (in parenthesis) for ease of comparison with Table IV.

TABLE VI

ANNUAL BENEFITS AND NET PRESENT VALE OF BENEFITS PRODUCED BY THE DIFFERENT SCENARIOS

\begin{tabular}{|l|c|c|c|c|}
\hline Scenario & $\begin{array}{c}\text { Fuel } \\
\text { saving }\end{array}$ & $\begin{array}{c}\mathrm{CO}_{2} \text { at } \\
€ 20 / \text { ton }\end{array}$ & $\begin{array}{c}\text { Renewable } \\
\text { revenue }\end{array}$ & $\begin{array}{c}\text { Total } \\
\text { Benefit }\end{array}$ \\
\hline \hline 2.Efficiency & $€ 264,503$ & $€ 25,980$ & - & $€ 290,483$ \\
(NPV €million) & $(2.57)$ & $(0.25)$ & - & $(2.82)$ \\
\hline 3. Wind50\% & $€ 415,521$ & $€ 78,360$ & $€ 568,467$ & $€ 1,062,348$ \\
(NPV €million) & $(4.04)$ & $(0.76)$ & $(5.52)$ & $(10.32)$ \\
\hline 4. Wind+Wave50\% & $€ 419,808$ & $€ 78,360$ & $€ 467,192$ & $€ 965,360$ \\
(NPV €million) & $(4.08)$ & $(0.76)$ & $(4.54)$ & $(9.38)$ \\
\hline 5.Wind+Wave100\% & $€ 590,825$ & $€ 107,480$ & $€ 467,192$ & $€ 1,165,497$ \\
(NPV €million) & $(4.24)$ & $(0.79)$ & $(4.54)$ & $(9.56)$ \\
\hline
\end{tabular}

Comparing Tables V and VI it is clear that if all benefits are included, the only scenario to produce positive net benefits is the 'Efficiency' scenario. In fact, even if just the fuel savings are considered, this scenario produces significantly higher benefits than costs.

The 'Wind 50\%' scenario, while displaying negative NPV, is the next closest scenario to breaking-even. The capital costs of wind in this scenario (3.2 MW of wind) represent 23\% of the total cost. Given the high level of net export in this scenario, perhaps a more feasible option for the Islands would be a lower wind penetration than $3.2 \mathrm{MW}$ combined with the efficiency measures and demand technologies. Thus, after efficiency measures are implemented it is recommended that the next step to a smart-network would be the deployment of demand technologies, the installation of smart meters (and the associated control algorithm as described in this paper), and the redevelopment of the Inis Meain wind farm (albeit at a smaller scale than $3.2 \mathrm{MW}$ ). In terms of prioritising demand technologies, it is recommended that due to the high and inefficient heat demand on the Islands versus the relatively low transport demand, that air-source heat pumps are adopted before electric vehicles. The combined cost of the heat pumps (capital and O\&M) is just 15\% (and with current subsidies, $11 \%$ ) of the total cost of the electric vehicles and would represent a significantly more economical approach to achieving a smart energy network than through electric vehicle deployment.

The high capital and O\&M costs of the wave device are likely to make scenarios 3 and 4 less viable in the short to medium term for the Islands. Also, the incremental benefit of moving from $50 \%$ to $100 \%$ demand technologies is significantly less than from $0 \%$ to $50 \%$. By comparing scenarios 4 and 5 we see that the NPV of the benefit of increasing from $50-100 \%$ penetration is $€ 0.2$ million, whereas the additional cost (from Table V) is $€ 8.8$ million.

\section{B. Implementation Challenges and Options}

The system requires knowledge of the total electricity demand of the islands. The simplest way to achieve this is to install monitoring equipment at the island end of the interconnector to the mainland. A loss factor could be applied to the readings to take account of any distribution losses on the islands. Each home would have a home area network which would integrate each of the flexible demand components on the premises, potentially employing a communications protocol such as Zigbee [32] to a dedicated control hub or other appropriate smart meter device. The data to be collected by each would be the availability and charge state of the electric vehicle and Availability of heat pump and heat store.

The smart grid system proposed here would utilise a time of day price in order that the required electricity from the EVs and heat pumps is acquired at the cheapest hours of the day. The exact configuration of this price signal depends on the manner in which the system is operated. If predetermined time of use tariffs are employed then there is price certainty in advance and the communications link would not be required. If a time varying uncertain electricity price was available then a link would be required to ensure the use of accurate and upto-date pricing information. The response time of the system is an important consideration. As this system is not currently being proposed as a resource to aid system operation, the requirements are less onerous than they might otherwise be.

The main requirement of the system is that it is reliable and has up to date information on the island electricity demand and renewable output. Forecasts of this information for the proceeding hours is also a requirement. The use of any forecast will inevitably lead to an error, but with an extensive database of historical information this error can be minimised. The time 
resolution used in the simulated system is an hour. It is feasible to operate the system on a higher resolution and may be wise given that there can be high wind variability within an hour. However, the main uncertainties surround the actual flexible demand elements as they are still maturing technologies and the ability to dispatch actively and interrogate them for the required data remains unknown.

\section{Significance of results for Ireland as a whole}

Ireland as a whole is currently pursuing a range of initiatives aimed at increasing renewable energy penetrations, improving energy efficiency and increasing the electrification of the transport sector. As such, a smart network on the Aran Islands could be viewed as a pilot scheme for the future of the energy sector of Ireland as a whole. However, comparisons should be made with extreme caution as the two systems, the Aran Islands and the island of Ireland, are very different. The breakdown of residential, commercial, industrial, transport and agricultural energy demand on the Aran Islands is markedly different to that on the Irish mainland. This is clearly seen in Figure 2 for the residential sector.

The differences between the Aran Islands and the island of Ireland are particularly important when it comes to the electricity system. Established technical challenges of operating a power system with high penetrations of renewables, such as inertial support, reactive power support and transmission system adequacy do not apply to Aran Island network. In addition, this report investigates scenarios where the installed generation capacity on the Aran Islands is increased to 2.61 $\mathrm{kW}$ per capita. The current level for the island of Ireland is $0.63 \mathrm{~kW}$ per capita. Interconnection also plays a key role in the integration of renewable energy and the Aran Islands, with a $3 \mathrm{MW}$ cable to the mainland, has a significantly higher import/export potential than the island of Ireland.

Thus, the results and methodologies illustrated in this paper should be interpreted in the context of the Aran Islands only, and should not be considered to be representative of potential for Ireland as a whole.

\section{CONCLUSIONS}

This paper investigates the potential of a smart energy network on the Aran Islands and includes an energy assessment of current practice, a resource assessment and a simulation of future demand technologies within a smart-network. It was found that the Aran Island communities consume significantly more energy for heating use than the Irish residential sector. In particular, the Aran Islands have a very high dependence on coal.

A wind resource assessment concluded that despite a high wind resource, there is no potential for developing a new wind farm site on the Islands as the majority of the surface area of all three islands are designated as National Heritage Areas (NHAs) and Special Areas of Conservation (SACs). The most practical option for increasing the wind penetration on the islands would be a redevelopment of the existing Inis Meáin wind farm. A tidal resource assessment found that the depth of the water and the velocity of the currents around the Aran Islands are unsuitable for the development of currently available tidal stream devices. A wave energy resource assessment found that the waters around the Aran Islands have a significant wave resource potential, with initial estimates of an annual accessible resource of $153.4 \mathrm{GWh}$.

A key component in the proposed smart network is a central optimisation engine which controls the timing of certain elements of electricity demand based on available renewable energy and minimum cost. An optimisation model such as this would be required in the roll-out of the smart network scheme and is developed in this paper to simulate a range of renewable energy and demand technology scenarios. It was found that the increased electrification of the energy usage on the islands, through heat pumps and electric vehicles, leads to a significant compression of total energy demand, as these technologies are significantly more efficient than current practices. A $100 \%$ roll-out of heat pumps and electric vehicles compresses total energy demand (across the electricity, heat and transport sector) on the islands by over 66\%. Despite this compression of energy demand, it was found that in the simulated scenarios the only scenario to produce positive net benefits involved increases in insulation and improvements in electrical efficiency. These efficiency measures should represent the first step in any smart-network scheme.

After efficiency measures are implemented it is recommended that the next step to a smart-network would be the deployment of demand technologies, the installation of smart meters (and the associated control algorithm as described in this paper), and the redevelopment of the Inis Meain wind farm (but at a smaller scale than the $3.2 \mathrm{MW}$ simulated here). In terms of prioritising demand technologies, it is recommended that due to the high and inefficient heat demand on the Islands versus the relatively low transport demand, that air-source heat pumps are adopted before electric vehicles. The combined cost of the heat pumps (capital and O\&M) is just $15 \%$ of the total cost of the electric vehicles and would represent a significantly more economical approach to achieving a smart energy network than through electric vehicle deployment. The high capital and O\&M costs of currently available wave devices make this option less viable in the short to medium term for the Islands. Also, in the roll-out of demand technologies, the incremental benefit of moving from $50 \%$ to $100 \%$ penetration is significantly less than from $0 \%$ to $50 \%$, thus further study is recommended prior to the full deployment of these technologies.

\section{ACKNOWLEDGMENT}

The authors would like to gratefully acknowledge the extensive support offered by Dr. Alan Mullane of Ecar Energy in the preparation of the material for this publication. Thanks is also due for the assistance received from Sustainable Energy Authority of Ireland, in particular Graham Brennan, and also the cooperation of the Aran Island residents.

\section{REFERENCES}

[1] E. Kolbert, "The island in the wind: a Danish community's victory over carbon emissions," The New Yorker, July 2008. 
[2] International Energy Agency (IEA), "Implementing agreement for cooperation in the research, development, and deployment of wind energy (iea wind). annual report, chapter 17: Norway," Available: http://www.ieawind.org, 2004.

[3] Scottish and Southern Energy, "Facilitate generation connections on orkney by automatic distribution network management," Available: http://www.dti.co.uk, no. CONTRACT NUMBER: K/EL/00311/00/00, 2004.

[4] Directive 2009/28/EC of the European Parliament and of the Council of 23 April 2009, "on the promotion of the use of energy from renewable sources and amending and subsequently repealing Directives 2001/77/EC and 2003/30/EC ," Available: http://eurlex.europa.eu/LexUriServ/LexUriServ.do?uri=CELEX:32009L0028:EN:NOT

[5] Department of Transport, Republic of Ireland, "Smarter travel, a sustainable transport future: a new transport policy for ireland 2009-2020," Available: http://www.transport.ie/upload/general/11284-0.pdf, 2010.

[6] Google, "Image from Google Maps," http://maps.google.com.

[7] Sustainable Energy Authority of Ireland (SEAI), "Energy in the residential sector," Available: http://www.seai.ie/Publications, 2008.

[8] Central Statistics Office (CSO), "Household budget survey 2004-2005," Available: http://www.cso.ie, 2007.

[9] Sustainable Energy Authority of Ireland (SEAI), "Energy in Ireland key statistics," Available: http://www.seai.ie/Publications, 2008.

[10] Scottish and Southern Energy, "SSE shetland project," Available: http://www.sse.com/shetland/, 2012.

[11] SEAI, "Wind atlas," Available: http://www.seai.ie, 2011.

[12] Sustainable Energy Authority of Ireland (SEAI), "Renewable energy resources in Ireland for 2010 and 2020," Available: http://www.seai.ie, vol. Report No. 4P305A-R5, Nov 2004.

[13] European Commission, "Council Directive 92/43/EEC of 21 May 1992 on the conservation of natural habitats and of wild fauna and flora," Available: http://ec.europa.eu, 1992.

[14] National Parks and Wildlife Service, Ireland, "Maps and data," Available: http://www.npws.ie/mapsanddata/.

[15] Integrated mapping for the Sustainable Development of Ireland's Marine Resource (INFOMAR), "Galway bay survey," Available: http://www.infomarie/surveying/Bays/Galwayv1.php.

[16] G. Bryans, B. Fox, P. Crossley, T. Whittaker, and M. O'Malley, "Tidal stream resource and impact assessment for ireland," in International Conference on Advanced Power System Automation and Protection, Korea, Juju Island, Korea, 2004.

[17] Sustainable Energy Authority of Ireland (SEAI), "Tidal and current energy resources in Ireland," Available: http://www.seai.ie, 2008.

[18] Marine Institute and Sustainable Energy Ireland (SEI), "Accessible wave energy resource atlas: Ireland," Available: http://www.marine.ie, 2005.

[19] Pelamis wave power, http://www.pelamiswave.com/.

[20] Irish Marine Institute, "Galway bay wave energy test site," Available: http://www.marine.ie/home/services/operational/oceanenergy/.

[21] D. Kavanagh, A. Keane, and D. Flynn, "Challenges posed by the integration of wave power onto the irish power system," European Wave and Tidal Energy Conference, 2011.

[22] A. Clement, P. McCullen, A. Falcao, A. Fiorentino, F. Gardner, K. Hammarlund, G. Lemonis, T. Lewis, K. Nielsen, S. Petroncini, M.-T. Pontes, P. Schild, B.-O. Sjostrom, H. C. Sorensen, and T. Thorpe, "Wave energy in europe: current status and perspectives," Renewable and Sustainable Energy Reviews, vol. 6, no. 5, pp. 405 - 431, 2002. [Online]. Available: http://www.sciencedirect.com/science/article/pii/S1364032102000096

[23] Sustainable Energy Authority Ireland, Ecar, ESB International, MEC, "Concept development of a wind and ocean powered smart network for the integrated supply of energy for electricity, heat and transport in irish island communities," Forthcoming at http://www.seai.ie, 2011.

[24] European Wind Energy Association (EWEA), "Wind energy - the facts," Available: http://www.ewea.org, 2006.

[25] Central Statistics Office Ireland, "Harmonised consumer price index," Available: http://www.cso.ie, 2006

[26] M. Carcas, "The pelamis wave energy convertor," in Hydrokinetic and wave energy technologies technical and environmental issues workshop. http://hydropowerinel.gov, Washington D.C., Oct 2005.

[27] Renault Kangoo Express, "http://www.renault.com/en/vehicules/renault/pages/kangooexpress-ze.aspx," 2011.

[28] Energy Saving Trust UK, "http://www.energysavingtrust.org.uk/homeimprovements-and-products," 2011.

[29] F. Lowe, "What you'll need and where to get it: heating that harnesses the earth's energy," http://www.telegraph.co.uk/earth/3297938/Whatyoull-need-and-where-to-get-it.html, 2007.
[30] Sustainable Energy Authority Ireland, "Better energy homes scheme," http://www.seai.ie/Grants/, 2011.

[31] Commission for Energy Regulation, "Smart metering cost-benefit analysis and trials findings report (CER 11/080)," $\quad$ http://www.cer.ie/en/information-centre-reports-andpublications.aspx?article $=5 d d 4 b c e 4-e b d 8-475 e-b 78 d-d a 24 e 4 f f 7339$, 2011.

[32] "Zigbee alliance," Available: http://www.zigbee.org/, 2011.

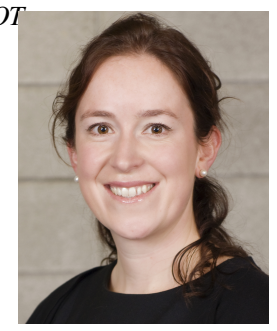

Eleanor Denny received a B.A. degree in Economics and Mathematics, an MBS degree in Quantitative Finance and a $\mathrm{Ph}$. D. degree from University College Dublin in 2000, 2002 and 2007 respectively. She is currently an Assistant Professor in the Economics Department at Trinity College Dublin and her research interests are in renewable energy integration, electricity markets and energy policy.

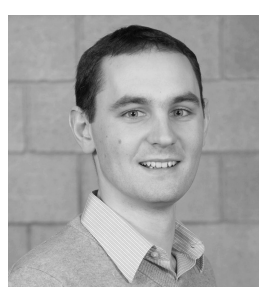

Andrew Keane (S'04, M'07) received B.E. and $\mathrm{Ph} . \mathrm{D}$. degrees in Electrical Engineering from University College Dublin in 2003 and 2007 respectively. $\mathrm{He}$ is a lecturer with the School of Electrical, Electronic and Communications Engineering, University College Dublin with research interests in power systems planning and operation, distributed energy resources and distribution networks. 